human language and a set of parameters that characterize possible variation among languages. The acquisition of language consists largely of fixing the values of these parameters on the basis of clues in the input. Importantly, this theory predicts that there are logically possible, but linguistically impossible, mistakes that children cannot make.

The parallel with birdsong is striking. Many birds have songs that develop appropriately only after interaction with conspecifics: the song is partly innate and partly dependent on experience. Nightingales, like children, only make mistakes that correspond to patterns that could occur as possible song elements for their species, just as children only make mistakes that are licensed by universal grammar.

We are evolutionarily closer to birds than to bees, but we are closer still to other primates. Their systems of communication, however, are less similar to human language than is popularly supposed. Vervet monkeys have distinct alarm calls for leopards, eagles and snakes. These calls can be extended to new types of threat - humans, for instance - and they are under some degree of voluntary control, yet they do not seem to 'refer' to the respective animals in the way we refer with our language. The calls can affect behaviour but not knowledge. Similarly, attempts to teach American Sign Language to chimpanzees have made it clear that, although human infants read intentions into the actions of others, chimps never do.

\section{IMAGE UNAVAILABLE FOR COPYRIGHT REASONS}

\title{
Aventis Science Book Prize shortlist announced
}

The Royal Society has announced the shortlist for this year's Aventis Prizes for Science Books' General Prize, which celebrates the very best in popular science writing for adults.

Critical Mass by Philip Ball (William Heineman) takes a look at the application of physics to the collective behaviour of society. "This book is impressively clear and breathtaking in scope... For anyone who would like to learn about the intellectual ferment at the surprising junction of physics and social science, Critical Mass is the place to start." Steven Strogatz (Nature 428, 367-368; 2004).

Robert Winston's The Human Mind (Bantam Press/Transworld) is an examination of the workings of our brains for an adult audience, inspired by his recent television series. His book What Makes Me, Me? (Dorling Kindersley),
To complement his critique of 'animal language', Anderson also outlines what is special about human language: in a word, syntax. Our vocabularies are dramatically larger than those of other animals, and our sound systems are more complex, but the essential design property of human language is syntax - the way we use combinations of words to convey meaning. This concept is alien to the communication systems of other species.

What animals learn is impressive and their cognitive abilities may be remarkable. But they never master anything like a human language and seem incapable of doing so: the complexity of their grammar is not remotely comparable to ours. This complexity is exemplified at length in the book, but two examples should suffice. First, the essence of syntax is recursion: the possibility of including one sentence inside another ad infinitum. For example: [Anderson discusses the claim that [many people think that [animals can talk]]]. Second, we all have subtle and consistent intuitions not only of what is possible in our language, but also of what is impossible. In [John expects to visit him], "John" and "him" must refer to different people, but consider this: [I wonder who [John expects to visit him]]. Here, "John" and "him" can, but need not, refer to the same individual. Judgements such as these have no parallel in the communication systems of other animals.

Anderson's elegant book contains a host of other insights and observations. He concludes that, just as the dance of bees, the song of birds and the calls of monkeys are unique to their respective species, so human language is unique to us.

Neil Smith is in the Department of Phonetics and Linguistics, University College London, Gower Street, London WC1E 6BT, UK. which takes a wider view of how the human body functions for a younger audience, has been shortlisted for the Junior prize.

In The Ancestor's Tale (Weidenfeld \& Nicolson), Richard Dawkins "views species as pilgrims marching into the past, joining each other genetically on a 3-billion-year journey to evolution's Canterbury: the first 'replicator'”. Jerry Coyne (Nature 431, 903-904; 2004).

In Matters of Substance (Penguin, Allen Lane), Griffith Edwards presents a lucid account of drug use and control, taking the radical view that the effect of any drug is just as dependent on the social, historical and psychological context as on its chemical structure.

In The Earth (HarperCollins), Richard Fortey "offers a clear, graphic and entertaining exposition of the manner in which, over an eon, the observed geological phenomena have achieved their present state. And he forcefully reminds us that events remotely embedded in deep time may yet be highly relevant as determinants for the lifestyles of modern human communities." Gordon L. Herries Davies (Nature 428, 697-698; 2004).

A review of Why Life Speeds Up As You Get Older by Douwe Draaisma (Cambridge University Press), an examination of the nature of memory, will appear in next week's issue of Nature.

The General Prize judging panel consists of author Bill Bryson, who won in 2004, weather forecaster Lisa Burke, Sian Ede,who is a renowned authority on art and science interactions, neurophysiologist Mark Lythgoe, and poet Ruth Padel. The winners will be announced on 12 May 2005. 